\title{
HISTOMORPHOLOGICAL SPECTRUM OF CENTRAL NERVOUS SYSTEM TUMOURS- A THREE-YEAR RETROSPECTIVE DESCRIPTIVE STUDY IN A TERTIARY CARE CENTRE
}

\author{
Narmadha $R^{1}$, Dhanalakshmi $S^{2}$, Priyadharshini $M^{3}$, Rajesh Natraj A. $P^{4}$, Subitha 5 , Padmavathi $S^{6}$ \\ ${ }^{1}$ Assistant Professor, Department of Pathology, Madras Medical College, Chennai. \\ ${ }^{2}$ Assistant Professor, Department of Pathology, Madras Medical College, Chennai. \\ ${ }^{3}$ Assistant Professor, Department of Pathology, Madras Medical College, Chennai. \\ ${ }^{4}$ Assistant Professor, Department of Pathology, Madras Medical College, Chennai. \\ ${ }^{5}$ Assistant Professor, Department of Pathology, Madras Medical College, Chennai. \\ ${ }^{6}$ Professor, Department of Pathology, Madras Medical College, Chennai.
}

ABSTRACT
BACKGROUND
CNS tumours are considered to be among the most notorious of all cancers. There is no accurate epidemiology of these CNS
tumours in South India which makes policy making for tumour screening and early treatment difficult. The purpose of this study is
to provide the spectrum of CNS tumours in a tertiary care centre in Chennai.

\section{MATERIALS AND METHODS}

This retrospective descriptive study was carried out at Department of Neuropathology, Madras Medical College, Chennai over a period of 3 years. A total of 890 cases who were diagnosed with CNS tumours on histopathology, registered between 2013 and 2015, were included and classified according to WHO 2007 classification with grading. Immunohistochemistry was done in needed cases.

\section{RESULTS}

A wide range of histopathological spectrum of CNS tumours was observed. Overall astrocytic tumours (36.1\%) were the most common followed by meningeal tumours (24\%) and metastatic tumours (9\%). Males exceeded females in most of the CNS tumour types, except in meningeal tumours and tumours of cranial and paraspinal nerves.

\section{CONCLUSION}

Rising global trends of incidence of CNS tumours, irrespective of age and gender have been observed. The present study highlights the histological diversity in CNS tumours in both genders and all age groups. Based on this study, glioblastoma multiforme is the most common CNS tumour in our setup.

\section{KEYWORDS}

Central Nervous System, Astrocytoma, Meningioma, WHO.

HOW TO CITE THIS ARTICLE: Narmadha R, Dhanalakshmi S, Priyadharshini M, et al. Histomorphological spectrum of central nervous system tumours- A three-year retrospective descriptive study in a tertiary care centre. J. Evolution Med. Dent. Sci. 2017;6(43):3362-3366, DOI: 10.14260/Jemds/2017/728

\section{BACKGROUND}

Central Nervous System (CNS) neoplasms are rarest tumours accounting for $1-2 \%$ of all neoplasms. There is a substantial increase in incidence of CNS tumours over recent years owing to improvements in diagnostic modalities. The annual global incidence of primary brain tumours is $\sim 3.7 / 1,00,000$ for males and 2.6/1,00,000 for females. ${ }^{1}$ GLOBOCAN project (2012) estimates the incidence of CNS neoplasms at $1.8 \%$ \& mortality rate at $2.3 \%$ for the world. For India, the incidence is $1.9 \%$ and mortality rate is $2.2 \% .^{2}$ This rate is more in developed countries than in developing countries. The highest incidence and mortality rates were more in developed regions than in developing countries. ${ }^{2}$ This could be due to underreporting of cases and availabilities of diagnostic modalities in developing nations.

Financial or Other, Competing Interest: None.

Submission 21-04-2017, Peer Review 16-05-2017,

Acceptance 22-05-2017, Published 29-05-2017.

Corresponding Author:

Dr. Narmadha $R$,

\#15, Second Cross St.

Mahalakshmi Nagar,

Adambakkam, Chennai-88.

E-mail: narmiram2@gmail.com

DOI: $10.14260 /$ jemds $/ 2017 / 728$
The aetiological factors, common types of tumours, prognostic factors and response to treatment varies in different geographic areas due to genetic and environmental factors. So a complete understanding of descriptive epidemiology of any particular disease is important to devise plans for prevention, early diagnosis and treatment protocols. ${ }^{3}$ In developing countries like India, hospital based prevalence data forms the major source of disease estimate. The main aim of this study is to analyse the epidemiology of CNS tumours in our hospital setup which will form a useful tool for further management of these cases.

\section{MATERIALS AND METHODS}

This is a retrospective descriptive study of CNS tumours conducted over a period of 3 years from Jan. 2013 - Dec. 2015 in Institute of Neuropathology, Madras Medical College, Chennai. The patients included in this study were selected based on specific inclusion and exclusion criteria. A brief clinical history and investigation details were obtained.

\section{Inclusion Criteria}

All cases of CNS tumours submitted for histopathology examination were included irrespective of age and sex of the patient. 


\section{Exclusion Criteria}

All non-neoplastic cases, those with incomplete clinical history, ill fixed and inadequate specimens were excluded from the study.

890 cases of CNS tumours were sent for histopathology examination over a period of 3 years. The biopsy materials were processed routinely and thin 4-5 micron sections were subjected for examination. The diagnosis was made on histological examination of processed tissue. All tissues were subjected to proper fixation with adequate fixative, subjected to dehydration and clearing followed by wax impregnation. 45 microns thin sections were cut and Haematoxylin and Eosin staining was done. Immunohistochemistry was done whenever needed. Tumours were classified and graded based on WHO 2007 classification. The relative frequencies of different types of tumours, their age and sex distribution were analysed.

\section{RESULTS}

During the three-year period of Jan. 2013 - Dec. 2015, 1420 cases were sent to Institute of Neuropathology, Madras Medical College out of which 890 cases (63\%) were neoplastic. The rest were non-neoplastic and inconclusive. CNS tumours showed a slight male predominance with the ratio of 1.13:1. Majority of cases presented as space occupying lesion in brain (89\%).

Tumours were common in third and fourth decades of life accounting for $43 \%$ of cases. The most common site of involvement is cerebral hemisphere (54\%) especially frontal lobe followed by Cerebellopontine angle.

Overall CNS tumours were most common in fourth followed by third decades of life and least common were in children less than 1 year and elderly individuals above 70 years of age.

In all age groups, the most common tumours were astrocytic tumours followed by meningeal tumours in adults and embryonal tumours in children and adolescents. In men astrocytic tumours were common followed by meningeal tumours whereas in women it was vice versa. Metastatic tumours were common after fifth decades of life most commonly adenocarcinoma from lung followed by breast and colorectal cancers. No cases of metastatic deposits were reported in less than 30 years.

Among the astrocytic tumours, common tumour in children and adolescents was pilocytic astrocytoma. In adults and elderly age group, glioblastoma multiforme was common. Overall grade 4 tumours were commonest accounting for $51 \%$ of astrocytic tumours and grade 3 tumours were least common accounting for $12 \%$ of all cases. Glioblastoma multiforme was common in fifth decade of life. In children less than one year of age, only pilocytic astrocytomas were seen accounting for $0.3 \%$ of all cases.

In meningiomas there was a female preponderance with grade 1 tumours being more common accounting for $76 \%$ of case, and grade 3 least common with only $4 \%$ of cases. Meningiomas were common in fourth and fifth decades of life with $57 \%$ of cases and least common in less than one year and above 70 years.

The most common diagnostic dilemma in our case series were between high grade astrocytic tumours and metastatic tumours for which GFAP was a useful immunohistochemistry marker along with cytokeratins.
Least common tumours were choroid plexus tumours, pineal gland tumours and germ cell tumours each accounting for $0.2 \%$ of all cases. No case of familial tumour syndromes was identified in our study.

\begin{tabular}{|c|c|c|}
\hline CNS Tumour & No. of Cases & Percentage \\
\hline Astrocytic Tumours & 321 & $36.1 \%$ \\
\hline Oligodendroglial Tumours & 40 & $4.5 \%$ \\
\hline Ependymal Tumours & 42 & $4.7 \%$ \\
\hline Choroid Plexus Tumours & 2 & $0.2 \%$ \\
\hline $\begin{array}{c}\text { Neuronal and Mixed } \\
\text { Neuronal-Glial Tumours }\end{array}$ & 16 & $1.8 \%$ \\
\hline Tumours of Pineal Region & 2 & $0.2 \%$ \\
\hline Embryonal Tumours & 37 & $4.3 \%$ \\
\hline $\begin{array}{c}\text { Tumours of Cranial and } \\
\text { Paraspinal Nerves }\end{array}$ & 103 & $11.6 \%$ \\
\hline Meningeal Tumours & 213 & $23.9 \%$ \\
\hline $\begin{array}{c}\text { Tumours of } \\
\text { Hematopoietic System }\end{array}$ & 9 & $1 \%$ \\
\hline Germ Cell Tumours & 2 & $0.2 \%$ \\
\hline Tumours of Sellar Region & 21 & $2.3 \%$ \\
\hline Metastatic Tumours & 82 & $9.2 \%$ \\
\hline Table 1 Relative Frequencies of CNS Tumours
\end{tabular}

Table 1. Relative Frequencies of CNS Tumours

\begin{tabular}{|c|c|c|c|}
\hline $\begin{array}{l}\text { Sl. } \\
\text { No. }\end{array}$ & $\begin{array}{l}<20 \text { Yrs. } \\
(16.2 \%)\end{array}$ & $\begin{array}{c}\text { 21-50 Yrs. } \\
(53.8 \%)\end{array}$ & $\begin{array}{c}>50 \text { Yrs. } \\
(30 \%)\end{array}$ \\
\hline 1. & $\begin{array}{l}\text { Astrocytic } \\
\text { Tumours } \\
(31.7 \%)\end{array}$ & $\begin{array}{c}\text { Astrocytic } \\
\text { Tumours (35\%) }\end{array}$ & $\begin{array}{c}\text { Astrocytic } \\
\text { Tumours (40.2\%) }\end{array}$ \\
\hline 2. & $\begin{array}{c}\text { Embryonal } \\
\text { Tumours }(22 \%) \\
\end{array}$ & $\begin{array}{c}\text { Meningioma } \\
(27.3 \%) \\
\end{array}$ & $\begin{array}{c}\text { Meningioma } \\
(28.9 \%) \\
\end{array}$ \\
\hline 3. & $\begin{array}{l}\text { Ependymal } \\
\text { Tumours } \\
(13.8 \%)\end{array}$ & $\begin{array}{c}\text { Tumours of } \\
\text { Cranial and } \\
\text { Paraspinal } \\
\text { Nerves }(14.2 \%)\end{array}$ & $\begin{array}{c}\text { Metastatic } \\
\text { Tumours (16.5\%) }\end{array}$ \\
\hline
\end{tabular}

Table 2. Common Tumours in Different Age Groups

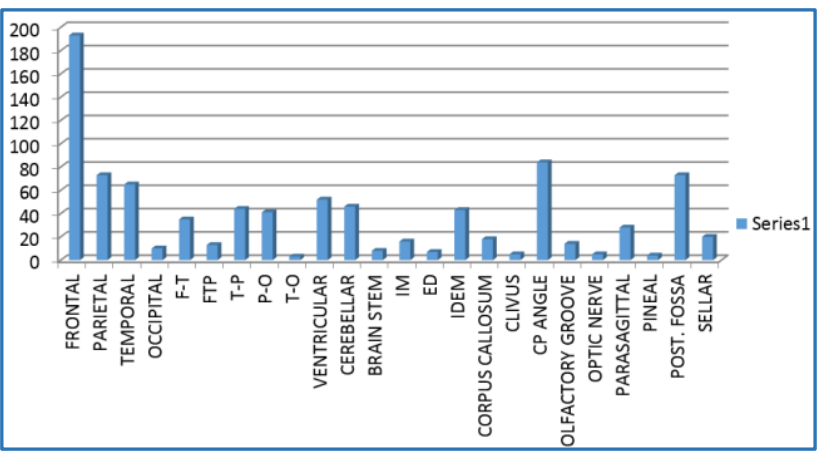

Chart 1. Site wise Distribution of CNS Tumours

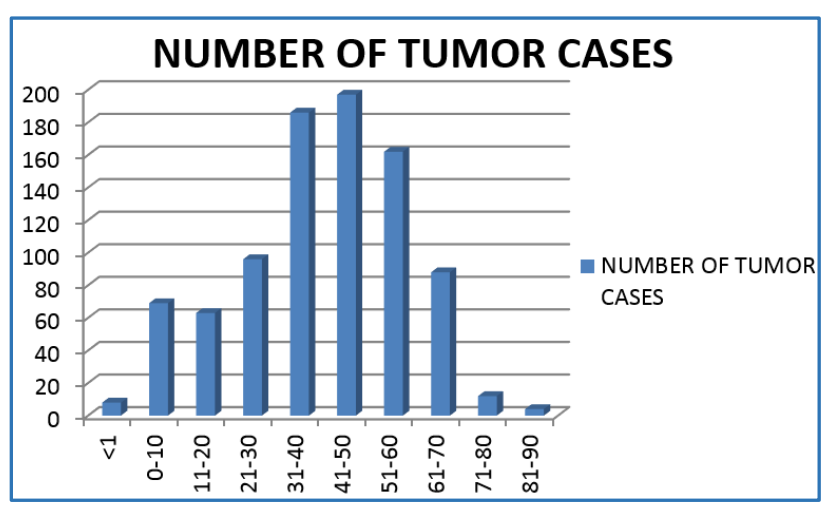

Chart 2. Age wise Distribution of CNS Tumours 


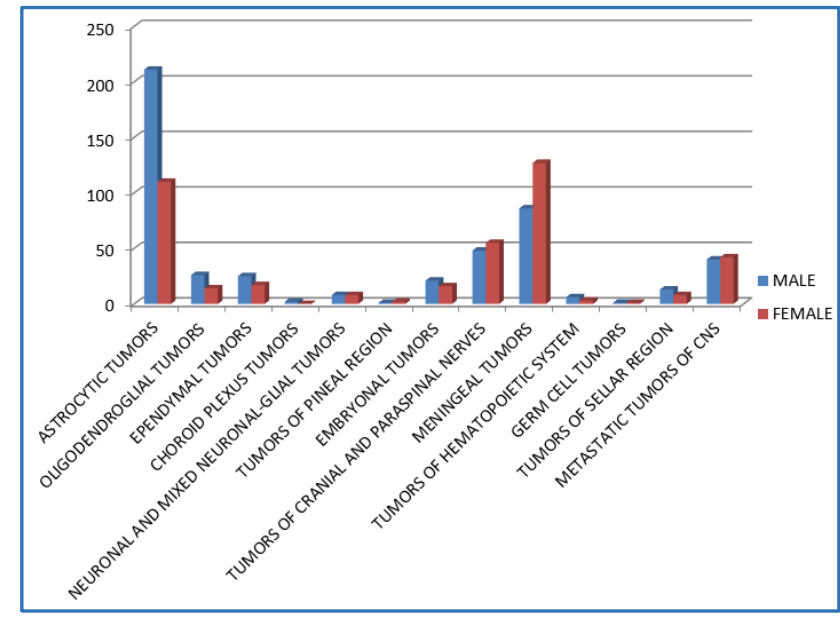

Chart 3. Relative Frequencies of Tumour in Male and Female

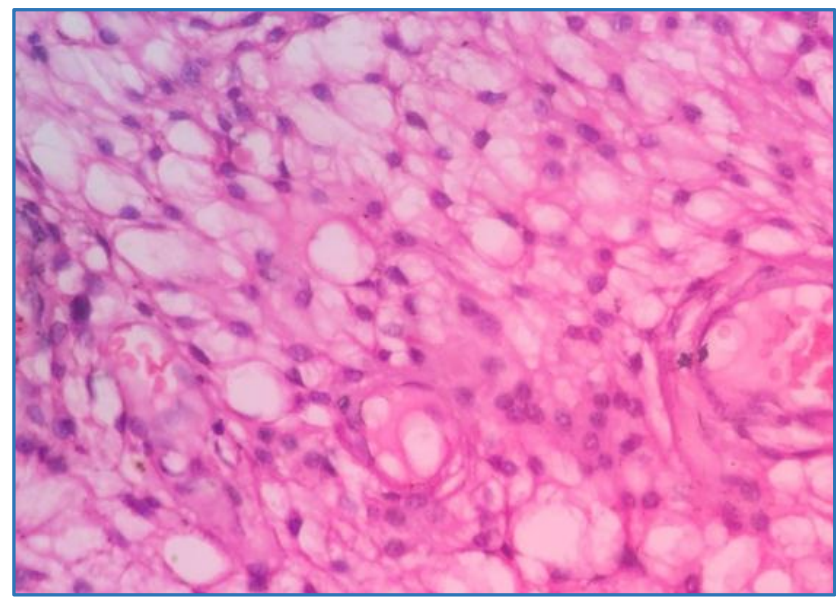

Picture 1. HPE Showing Cells with Clear Cytoplasm and Occasional Meningothelial Whorl in Clear Cell Meningioma

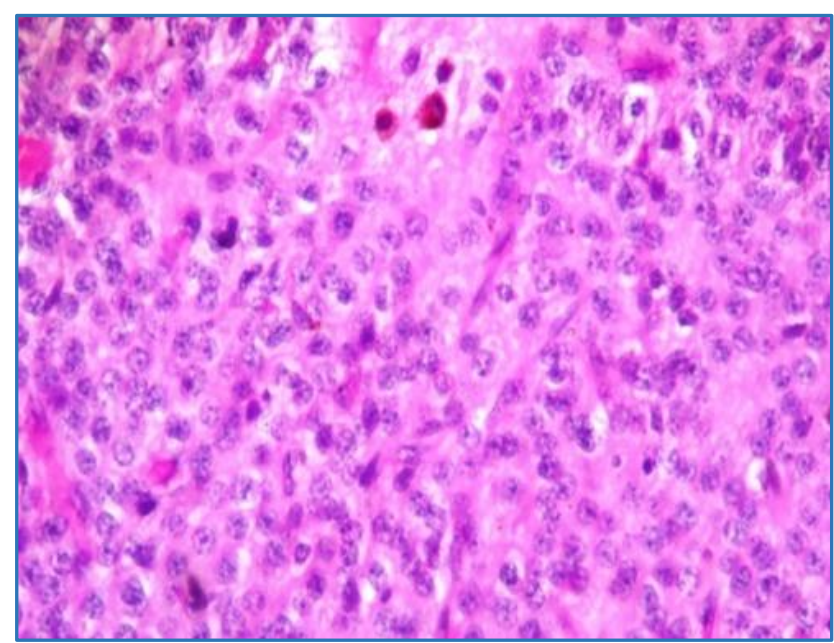

Picture 2. HPE Showing Homogenous Cells Separated by Delicate Vascular Stroma with Uniform Round Nuclei in Central Neurocytoma

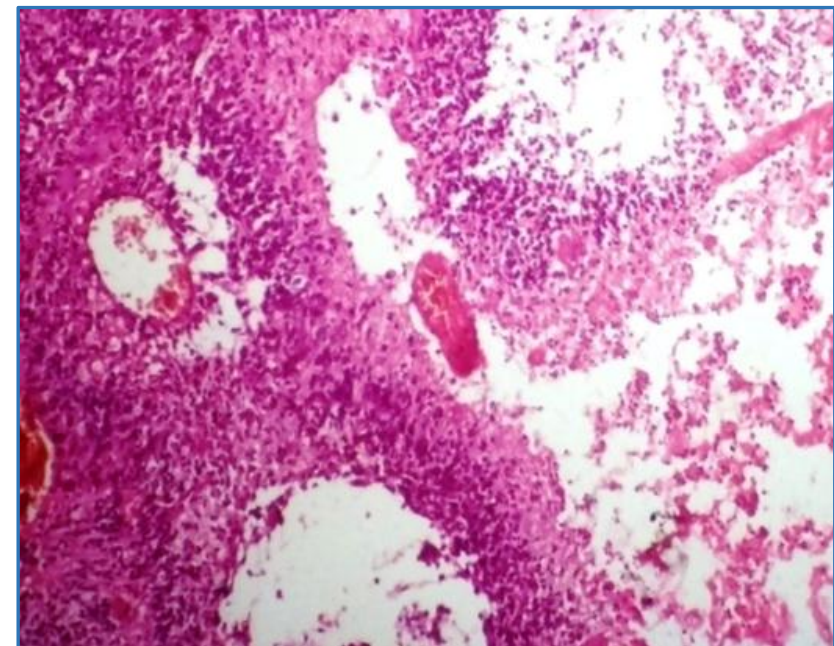

Picture 3. HPE showing Pseudopalisading around Central Zone of Necrosis in Glioblastoma Multiforme

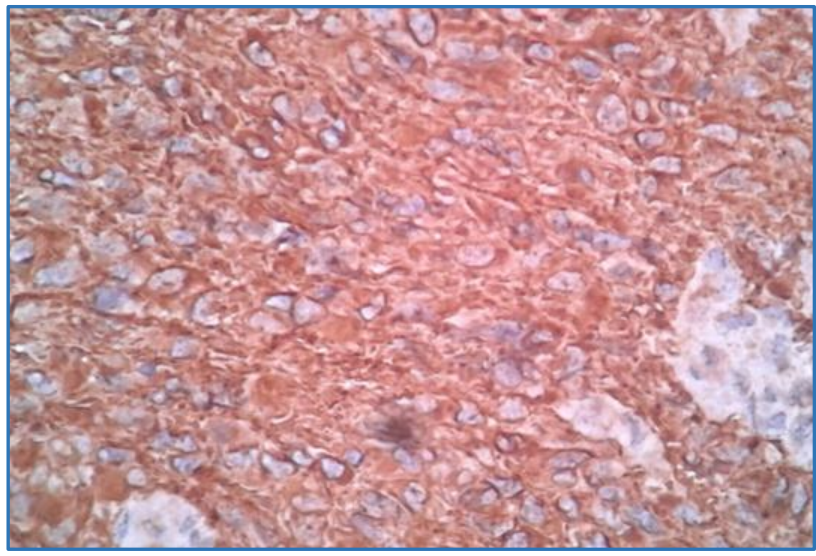

Picture 4. GFAP Positivity in $G B M$

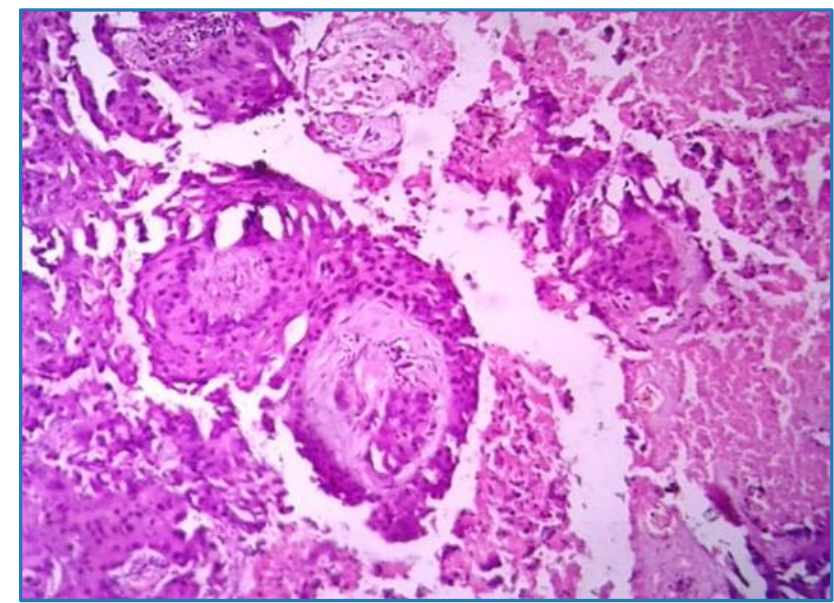

Picture 5. HPE Showing Tumour Cells Arranged in Glandular Pattern and Nests with Areas of Necrosis in Metastatic Carcinomas

\section{DISCUSSION}

CNS neoplasms represent a vast group of heterogeneous diseases, each with its own natural history. They include a wide range of tumours which originate from intracranial 
tissues, meninges and with varying grades from benign to highly aggressive and lethal malignant forms. The significance of CNS tumours is that even a benign tumour with nonlethal behavior in other sites can be life endangering because of their location in brain. It is important to distinguish these tumour subtypes as the treatment protocols and prognosis varies.

The overall prognosis depends on the type of neoplasm and age at diagnosis among many prognostic variables. $(4,5)$ The current study was designed to analyse the descriptive epidemiology of CNS neoplasms in a tertiary care institute. A study like this allows for continuous monitoring of time trends in the incidence of CNS neoplasms and relative frequencies of the tumour spectrum in the population.

WHO 2007 categorises tumours of Central Nervous System into fifteen types which includes Astrocytic tumours, Oligodendroglial tumours, Ependymal tumours, Choroid plexus tumours, other neuroepithelial tumours, Neuronal and mixed neuronal glial tumours, tumours of the pineal region, embryonal tumours, tumours of cranial and paraspinal nerves, meningeal tumours, tumours of hematopoietic system, germ cell tumours, familial tumour syndromes, tumours of sellar regions and metastatic tumours. ${ }^{6}$

The histopathological spectrum of CNS tumours varies in different age groups, geographic areas and between men and women.

The majority of CNS neoplasms are astrocytic tumours similar to other studies conducted by Jalai et $\mathrm{al}^{7}$ and Javaria et al ${ }^{8}$ but different from study conducted by Pidakala et al. ${ }^{9}$ The most malignant and frequent being glioblastoma multiforme, as also evidenced by our study. ${ }^{10,11}$

In previous studies, incidence rates were higher for men.1,2 However, in our study, there was only a slight male predominance (M:F-1.1:1). This trend of only slight difference in male female ratio could be due to environmental and ethnic factors. In astrocytic and oligodendroglial tumours, the male to female ratio was high being 2:1 similar to a study conducted in China and Pakistan. ${ }^{2}$

Astrocytic tumours occur more frequently in men whereas meningiomas occur predominantly in women, as was also seen in our study. ${ }^{1,10}$ In meningiomas male to female ratio was $1: 1.5$ similar to other studies. ${ }^{8}$

All age group of patients staring from infants to elderly individuals of eighth and ninth decades of life were affected. Most common age group was fourth followed by third decades which was similar to a study conducted in Punjab, India $^{12}$ and a decade earlier than other studies conducted in Pakistan. ${ }^{13}$ This difference in age group incidence could be attributed to both genetic factors and increase in diagnostic modalities and increasing awareness among patients.

Glioblastoma multiforme forms the largest series of astrocytic tumours and is common in fifth decades of life which is a decade earlier than international statistics. ${ }^{14}$.

In children astrocytic tumours were common followed by medulloblastoma and ependymoma similar to several other studies. ${ }^{15,16}$

Metastatic tumours account for $9.2 \%$ of all cases being common in elderly individuals above 50 years of age. The most common metastatic tumour was from lung similar to a study conducted by Sloan et $\mathrm{al}^{17}$ and Saha et al ${ }^{18}$ followed by metastasis from breast.
Most common diagnostic dilemmas in our study was between metastatic carcinomas and high grade gliomas. The immunohistochemistry panel including GFAP and cytokeratins was useful in discriminating the two similar to a study conducted by Goyal et al. ${ }^{19}$

This study may not be representative of entire population as it includes only cases from a single referral centre, but it adds to the statistical data available from other institutions. This study can be used to analyse the emerging and varying trends in CNS tumours, and a further detailed workup of genetic makeup of this tumour is essential to devise prognostic and therapeutic markers.

\section{CONCLUSION}

Astrocytic tumours are the commonest tumours in all age groups and both men and women in our study followed by meningiomas. There is a slight male preponderance. Glioblastoma multiforme is the commonest astrocytic tumour in this study. This study shows the varying trends of CNS tumour and paves way for further research to reveal the probable risk factors of CNS tumours including genotyping which helps for earlier diagnosis and development of newer treatment modalities for these tumours.

\section{REFERENCES}

[1] Chen L, Zou X, Wang Y, et al. Central nervous system tumors: a single center pathology review of 34,140 cases over 60 years. BMC Clinical Pathology 2013;13(1):14.

[2] Ferlay J, Soerjomataram I, Dikshit R, et al. Cancer incidence and mortality worldwide: sources, methods and major patterns in GLOBOCAN 2012. International Journal of Cancer 2015;136(5):E359-E86.

[3] Oliveria SA, Christos PJ, Berwick M. The role of epidemiology in cancer prevention. Proc Soc Exp Biol Med 1997;216(2):142-50.

[4] Davis FG, Freels S, Grutsch J, et al. Survival rates in patients with primary malignant brain tumors stratified by patient age and tumor histological type: an analysis based on Surveillance, Epidemiology and End Results (SEER) data, 1973-1991. Journal of Neurosurgery 1998;88(1):1-10.

[5] Lamborn KR, Chang SM, Prados MD. Prognostic factors for survival of patients with glioblastoma: Recursive partitioning analysis. Neuro-Oncology 2004;6(3):22735.

[6] Louis DN, Ohgaki H, Wiestler OD, et al. WHO classification of tumors of the nervous system. Lyon: IARC 2007:8-9.

[7] Jalali R, Datta D. Prospective analysis of incidence of central nervous tumors presenting in a tertiary cancer hospital from India. J Neurooncol 2008;87(1):111-4.

[8] Ahsan J, Hashmi SN, Muhammad I, et al. Spectrum of central nervous system tumours-a single center histopathological review of 761 cases over 5 years. J Ayub Med Coll Abbottabad 2015;27(1):81-4.

[9] Pidakala P, Inuganti RV, Boregowda C, et al. A five-year histopathological review of CNS tumours in a tertiary centre with emphasis on diagnostic aspects of uncommon tumours. J Evid Based Med Healthc 2016;3(51):2605-12. 
[10] Yeole BB. Trends in the brain cancer incidence in India. Asian Pac J Cancer Prev 2008;9(2):267-70.

[11] Aryal G. Histopathological pattern of central nervous system tumor: a three year retrospective study. Journal of Pathology of Nepal 2011;1(1):22-5.

[12] Nibhoria S, Tiwana KK, Phutela R, et al. Histopathological spectrum of Central Nervous System Tumors: a single centre study of 100 cases. International Journal of Scientific Study 2015;3(6): 130-4.

[13] Ayaz B, Lodhi FR, Hasan M. Central Nervous System Tumours: a hospital based analysis. Pak Armed Forces Med J 2011;61(1):61-4.

[14] Schwartzbaum JA, Fisher JL, Aldape KD, et al. Epidemiology and molecular pathology of glioma. Nat Clin Pract Neurol 2006;2(9):494-503.

[15] Jain A, Sharma MC, Suri V, et al. Spectrum of pediatric brain tumors in India: a multi-institutional study. Neurology India 2011;59(2):208-11.
[16] Arora RS, Alston RD, Eden TO, et al. Age-incidence patterns of primary CNS tumors in children, adolescents and adults in England. Neuro Oncology 2009;11(4):403-13.

[17] Barnholtz-Sloan JS, Sloan AE, Davis FG, et al. Incidence proportions of brain metastases in patients diagnosed (1973 to 2001) in the Metropolitan Detroit Cancer Surveillance System. Journal of Clinical Oncology 2004;22(14):2865-72.

[18] Saha A, Ghosh SK, Roy C, et al. Demographic and clinical profile of patients with brain metastases: a retrospective study. Asian Journal of Neurosurgery 2013;8(3):157-61.

[19] Goyal R, Mathur SK, Gupta S, et al. Immunohistochemical expression of glial fibrillary acidic protein and CAM5.2 in glial tumors and their role in differentiating glial tumors from metastatic tumors of Central Nervous System. Journal of Neurosciences in Rural Practice 2015;6(4):499-503. 